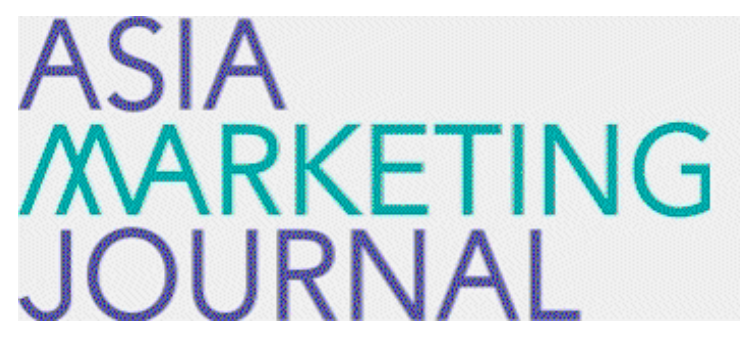

ASIA MARKETING JOURNAL

Volume 22 | Issue 2

Article 5

7-31-2020

\title{
ASIA MARKETING JOURNAL Vol.22 No.2 목차
}

Follow this and additional works at: https://amj.kma.re.kr/journal

Part of the Marketing Commons

\section{Recommended Citation}

(2020) "ASIA MARKETING JOURNAL Vol.22 No.2 목차," Asia Marketing Journal: Vol. 22 : Iss. 2 , Article 5. Available at: https://doi.org/10.53728/2765-6500.1358

This Article is brought to you for free and open access by Asia Marketing Journal. It has been accepted for inclusion in Asia Marketing Journal by an authorized editor of Asia Marketing Journal. 


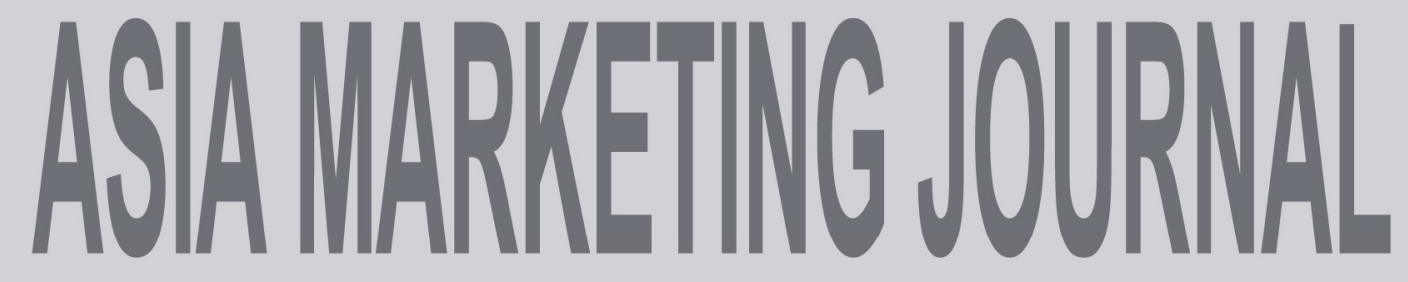

\section{Vol. 22 No. 02 July 2020}

\section{$<$ Research Paper $>$}

The Effect of Consideration Set on Market Structure

Jun B. Kim

1

Wear Your Heart on Your Sleeve: Exploring Moral Identity as a Moderator Across CSR Authenticity, Consumer Admiration, and Engagement in the Fashion Industry Edward Jung · Suna La

The Role of Imagery vs. Analytical Advertisement on New Products Evaluation Juyon Lee $\cdot$ Wujin Chu

\section{$<$ Case and Policy Research>}

Vying with IKEA: HANSSEM's Competitive Advantage at Marketing Frontier 